\title{
WASH Intervention Effects and Implications in Rural Schools and Communities of Georgia
}

\author{
${ }^{1}$ Metreveli Levan, ${ }^{2}$ Kuparadze Khatuna, ${ }^{3}$ Gabunia Luiza, ${ }^{4}$ Baramidze Levan, ${ }^{5}$ Gumbaridze Lia \\ ${ }^{1,2}$ Georgian Medical Group, ${ }^{1}$ BAU International University, Batumi, ${ }^{3,4,5}$ Tbilisi State Medical \\ University \\ Authors: \\ ${ }^{2}$ Khatuna Kuparadze, MD \\ Founder and Capacity Building Officer, Georgian Medical Group \\ ${ }^{3}$ Luiza Gabunia, MD, $\mathrm{PhD}$ \\ Associate Professor of Pharmacology, Tbilisi State Medical University \\ Levan Bramidze, MD, PhD, MPH \\ Professor of Public Health, Tbilisi State Medical University \\ Lia Gumbaridze, $\mathrm{MD}, \mathrm{PhD}$ \\ Researcher, Tbilisi State Medical University \\ Corresponding Author: \\ METREVELI Levan, MD, PhD, MPH \\ Chief of Party, Georgian Medical Group; Professor of Public Health, BAU International \\ University, Batumi \\ Address: 32 Paliashvili Street, Tbilisi 0179, Georgia \\ Telephone: +995-595-032263
}

doi: $10.51505 / \mathrm{ijmshr} .2021 .5312$

URL: http://dx.doi.org/10.51505/ijmshr.2021.5312

\begin{abstract}
The present article is a combination of research and policy analysis around Water, Sanitation and Hygiene (WASH) interventions implemented by Georgian Medical Group (GMG) in the period of 2015-2021 in rural schools and communities in two regions of Georgia: Adjara and Guria. The mentioned WASH efforts have been funded by the United States Agency for International Development (USAID) and the Coca-Cola Foundation through Global Water Challenge, New World and CARE International in the Caucasus. The shares in funding have been distributed as $85 \%$ USAID and $15 \%$ the Coca-Cola Foundation.
\end{abstract}

All three components of the effort proved to be quite successful i.e. 4,202 school children in the target regions have substantially improved water supply, toiletry, sanitation and hygienic habits 


\section{International Journal of Medical Science and Health Research}

Vol. 5, No. 03; 2021

ISSN: 2581-3366

and skills. Additionally, 330 teachers and 330 peer educators have been trained around WASH issues. Although we had no specific means to measure the long-term outcomes of the community mobilization component, the scale of project's media production outreach exceeded the initially planned limits (local and regional) as opposed to the dissemination at national level. The research attempted to measure the effectiveness of WASH interventions by applying the following methods: published evidence review, observation and participant survey.

The documented success of our WASH intervention approach as well as the available international evidence prompt us to consider the "Triple Element" (infrastructure, education and community mobilization) WASH in Schools principle as the optimal modality for implementing in low and middle income countries. Exclusion of any of these elements will adversely affect intervention's overall impact and importantly enough-its long-term sustainability. The "Triple Element" model seems to be easily scalable in Georgia and we also foresee the good prospects for its transferability to the countries with the similar socio-economic characteristics (the former Soviet Union states).

Keywords: Community Mobilization, Education, Infrastructure Rehabilitation, Wash

\section{Introduction}

The present article is a combination of research and policy analysis around Water, Sanitation and Hygiene (WASH) interventions implemented by Georgian Medical Group (GMG) in the period of 2015-2021 in rural schools and communities in two regions of Georgia: Adjara and Guria. The mentioned WASH efforts have been funded by the United States Agency for International Development (USAID) and the Coca-Cola Foundation through Global Water Challenge, New World and CARE International in the Caucasus. The shares in funding have been distributed as 85\% USAID and $15 \%$ the Coca-Cola Foundation.

Under both funding channels, we applied the identical approaches: 1. WASH infrastructure rehabilitation; 2. WASH education; and 3. Community mobilization. Altogether, 33 rural schools have been targeted in the regions of Adjara and Guria. The infrastructure component of the intervention has been focused on thorough assessment of the state of WASH units in the targeted schools. Particular attention was paid to the safety aspects and consistence of drinking water supply, sanitation, privacy and acceptability parameters of existing school toilets and the ways of septic water treatment. Under the educational component, three types of trainings have been used to reach school teachers, peer educators (high grade students) and children in all classes. There have been trained 33 groups in the first and second category. The groups consisted of 10 teachers/students. Each training used anonymous pre-and post-tests aimed at revealing a baseline knowledge on WASH issues (pre-test) and detecting the progress (post-test). There have been 19 multiple choice questions (MCQs) in teachers' and $13 \mathrm{MCQs}$ in students' tests. In total, trainings have been extended to 660 persons (330 teachers and 330 students). Additionally, the trained teachers delivered so called "Clean Hands Lessons" to all classes (4,202 students). The community mobilization component implied establishment of voluntary "WASH Committees" at schools with participation of students, parents, teachers, municipal and community leaders. 


\section{International Journal of Medical Science and Health Research}

Vol. 5, No. 03; 2021

ISSN: $2581-3366$

WASH committees served as centers of stewardship locally by overseeing the project implementation process and ensuring the long-term sustainability of achieved WASH effects. Besides committees, the project undertook a wide media campaign on safe WASH practices and proper handwashing techniques in TV, Internet and printed media, nationally and regionally and organized a series of local WASH events at targeted schools and communities.

The research attempted to measure the effectiveness of WASH interventions by applying the following methods: published evidence review, observation and participant survey. In the following sections, we will provide a review of WASH in Schools policies and experiences internationally with the special emphasis on their relevance to the needs and developments in Georgia, detailed description of each intervention component, presentation of a quantitative study conducted under the educational component, discussion and policy implications and conclusions.

\section{WASH policy and evidence review}

While the water, sanitation and hygiene situation for rural schools displays a wide variety of challenges (based on economic development, geography, climate, culture and politics) internationally, the solutions' typology is rather limited and encompasses a very narrow circle of interventions. Below, we will review the recent developments and highlight the most explicit practices available in the developing world. A special attention will be paid to cross-cutting issues, such as gender, environmental safety and socio-economic development.

The school textbook analysis in Kenia manifested the existing gaps regarding the sanitation and hygiene issues, particularly, handwashing and menstrual hygiene ("Kenyan School Book Knowledge for Water, Sanitation, Hygiene and Health Education Interventions," 2021). The similar tendency has been characteristic to Georgia's public sector of general education.

The WASH education does not assure the immediate positive shift in population health as it has been documented in a cross sectional pre-/post-study in Ethiopia (Gizaw et al., 2019). The epidemiologic effects, normally take a longer time and require a considerable consistence in implementing WASH educational interventions.

"The evidence showed that there is clear and strong evidence of effect of education and handwashing with soap in preventing diarrheal disease among children (consistent effect in four studies). In the largest well-designed study, children living in households that received plain soap and encouragement to wash their hands had a 53\% lower incidence of diarrhea (95\% CI, 0.35, 0.59)" (Brewster David et al., 2008).

A significant change in reduction of concentration of microbial agents was achieved by the proper handwashing education among primary school students, as a randomized controlled trial documented in a rural region of Turkey with a low socioeconomic level (Öncü et al., 2019).

Interesting results have been demonstrated by a study targeting children aged 6-11. The study tried to evaluate the handwashing messages elaborated by the children themselves. The messages 


\section{International Journal of Medical Science and Health Research}

Vol. 5, No. 03; 2021

ISSN: $2581-3366$

related with reminding and encouraging handwashing have been considered most effective (Rutter et al., 2020). Similar experience with student-made handwashing promotion posters has been documented in Kenya (Graves et al., 2011).

An amazing experience in elementary schools in Turkey has concluded that "handwashing skills and times increased after undergoing hand washing training using the DPDS (demonstration, puzzle, dance, song) method" (Ozcan et al., 2020).

"The results (of a study conducted in India) indicate that children (after taking WASH education courses) had an improved (54\%) understanding of the causes of bacterial disease and the health implications of not using adequate health-hygiene practices. Recommendations for the future development of resources include the use of a PAR (participatory action research) model of research, co-creation with end users, and working alongside local organizations and participants in order to access 'hard-to-reach' areas“ (Crosby et al., 2020). Similar results have been shown in a systematic review and the case-control studies regarding the formation of WASH behaviors in schools (Karon et al., 2017) (Tidwell et al., 2020).

$47 \%$ showed improvement of knowledge scores at the time of the post-test within the WASH educational effort targeted to 5,462 school children in Georgia, USA (Harrison, 2012).

A large-scale study conducted in South Korea suggests that "parent-child bonding and shared time are crucial in promoting children's hand hygiene" (Song et al., 2013).

Another series of WASH education interventions, being implemented in 15 developing countries, demonstrated that "the program had proved to be highly effective and amenable to cross-cultural adaptation " (Coates et al., 2010).

Improved infrastructure in school toilets and small nudges ("1. connecting latrines to the handwashing station via paved pathways that were painted bright colors; and 2. painting footprints on footpaths guiding students to the handwashing stations and handprints on stations") to necessitating (non-conscious decision making) proper handwashing proved to be the strong pre-determinants to increased handwashing rates and quality in two schools in Bangladesh (Dreibelbis et al., 2016).

An "after-intervention" study conducted in India underlined the importance of health clubs for achieving better maintenance of school toilets and higher rates of handwashing among students. The presence of parents and influential community members in health clubs proved to be good factors for the positive change. The same study had also expressed the concerns about building long-term sustainability of WASH intervention-achieved positive developments (Kochurani Mathew et al., 2009).

Another study from Botswana warns that even when the WASH topics are included in school curricula, "extra-curricular clubs in schools should be established to promote prohygiene behaviors and to facilitate adolescents' meaningful and sustained participation" (Thakadu et al., 2018). 


\section{International Journal of Medical Science and Health Research}

Vol. 5, No. 03; 2021

ISSN: 2581-3366

The holistic approach to WASH behavior change is widely supported by the available research works worldwide (Pasewaldt et al., 2019). A study from Kenia underlines that "results showed significant improvement in knowledge among students who received messages (hygiene messages) and tested water, compared to their counterparts who received intervention through hygiene messages only" (Nzengya, 2015). This is also supported by the research identifying cleanliness of school latrines (improved sanitation) only, without the other components of the holistic approach, had no significant influence over diarrheal disease incidence and missed school hours (Caruso et al., 2014). An integrated model of WASH intervention (improved infrastructure, safe drinking water and hygiene education) also displayed the reduction in incidence rates of Trachoma and other intestinal parasitic diseases among school children in rural Ethiopia (Gelaye et al., 2014).

A study of school WASH situation in Brazil underlines that besides the immediate benefits of WASH programs (improved infrastructure, safe water supply, better sanitation and hygiene), there are other not less important outcomes related to the fulfillment of rights to accessible, decent and acceptable conditions in school toilets, so that students and teachers feel that their dignity is not affected in the negative ways (Coswosk et al., 2019).

An analogous phenomenon to so called "Hawthorn Effect" ("Hawthorne Effect," 2021) was found in a research that documented a positive shift in WASH behaviors of younger siblings of school-going children who have been targeted by school WASH programs (Dreibelbis et al., 2014). In another study, in addition to the school-based findings, self-reported handwashing at critical times was found to be higher among household members of students from intervention schools (Vally et al., 2019).

Some authors propose antecedent and prospective methods of teaching handwashing. Glo Germ ${ }^{\mathrm{TM}}$, a UV-sensitive simulated germ lotion was used to show children how well they washed their hands (Jess \& Dozier, 2020) (Dingman et al., 2020).

The foregoing brief review serves as a proof of concept for our WASH interventions implemented in Georgia's rural schools and communities.

\section{WASH intervention components}

\subsection{WASH infrastructure rehabilitation}

The technical evaluation has been conducted at each target school. It involved preparing detailed description of WASH situation, water quality testing (before and after the infrastructure works), geological research of filtration properties of the ground (where necessary) and drafting descriptions of construction/rehabilitation works. None of the target schools had wellfunctioning indoor toilet, except tone. Students and teachers have been using outdated latrines or indoor toilets with poor sanitation. Water tests revealed biological contamination (E. Coli) at all sites (except one).

www.ijmshr.com

Page 122 


\section{International Journal of Medical Science and Health Research}

Vol. 5, No. 03; 2021

ISSN: $2581-3366$

In all schools, the indoor toilets have been either newly built or the existing ones have been rehabilitated. Additionally, special toilets were arranged for handicapped students (wherever such need was expressed and the physical space allowed to do so). At all sites, "Ultraviolet Lamps" were installed for water purification. In the majority of schools, septic chambers and filtration fields have been arranged. As a result of infrastructure rehabilitation, 4,202 students enjoy improved WASH conditions.

\subsection{WASH education}

WASH education was delivered in three distinct modalities: 1. Training of Trainers (ToTs). 10 teachers from each target school have participated in a 2-day WASH training; 2. Training of Peer Educators. 10 high grade students from each school took part; 3. "Clean Hands Lessons" were conducted in all classes by already trained teachers.

WASH habits have been evaluated through administering pre-and post-tests to the participants of ToTs and Peer Educator trainings. For this cluster, a small-scale quantitative study was performed.

\section{$\underline{\text { Study design and results: }}$}

The samples of 330 teachers and 330 students have been employed. A convenience sampling procedure has been used in the form of school administrations submitting participant lists.

In each training group, we calculated the number of correct answers to each question and pooled them into a joint data set. The variables used: a. School name; b. Test character (pre-/post-) (independent variables); c. Test scores for teachers; d. Test scores for students (dependent variables). In total, we consolidated 66 entries in each category of teachers and students.

The statistical analysis was performed using IBM SPSS Statistics (Version 23).

Descriptive statistics revealed the mean scores of both (pre-and post-) tests in each trainee category (teachers and students) (see Table 1).

Table 1

Means of group test scores for teachers and students

\begin{tabular}{lllllll}
\hline & N & Minimum & Maximum & Sum & Mean & Std. Deviation \\
\hline Score_Teachers & 66 & 4.11 & 10.00 & 487.22 & 7.3821 & 1.96620 \\
Score_Students & 66 & 2.46 & 10.00 & 432.36 & 6.5509 & 1.62373 \\
Valid N (listwise) & 66 & & & & & \\
\hline
\end{tabular}

The both trainee categories displayed different mean scores for pre-and post-tests. (see Table 2). 
International Journal of Medical Science and Health Research

Vol. 5, No. 03; 2021

ISSN: 2581-3366

Table 2

Mean scores for pre-and post-tests

\begin{tabular}{llll}
\hline Pre_Post_Test & Score_Teachers & Score_Students \\
\hline Pre-Test & Mean & 5.7164 & 5.4430 \\
& $\mathrm{~N}$ & 33 & 33 \\
& Std. Deviation & .88920 & .98726 \\
\hline Post- & Mean & 9.0479 & 7.6588 \\
Test & $\mathrm{N}$ & 33 & 33 \\
& Std. Deviation & 1.15721 & 1.35984 \\
Total & Mean & 7.3821 & 6.5509 \\
& $\mathrm{~N}$ & 66 & 66 \\
& Std. Deviation & 1.96620 & 1.62373 \\
\hline
\end{tabular}

An independent samples $t$-test has been performed for the test variables: Score_Teachers and Score-Students with the group variable - Pre_Post_Test. Both test variables displayed that the post-test mean scores have been significantly different from the ones of pre-test $[p<.001, C I$ 95\%]. This can be interpreted as a tangibles progress being achieved during the trainings of teachers and students (see Table 3).

Table 3

Independent samples t-test

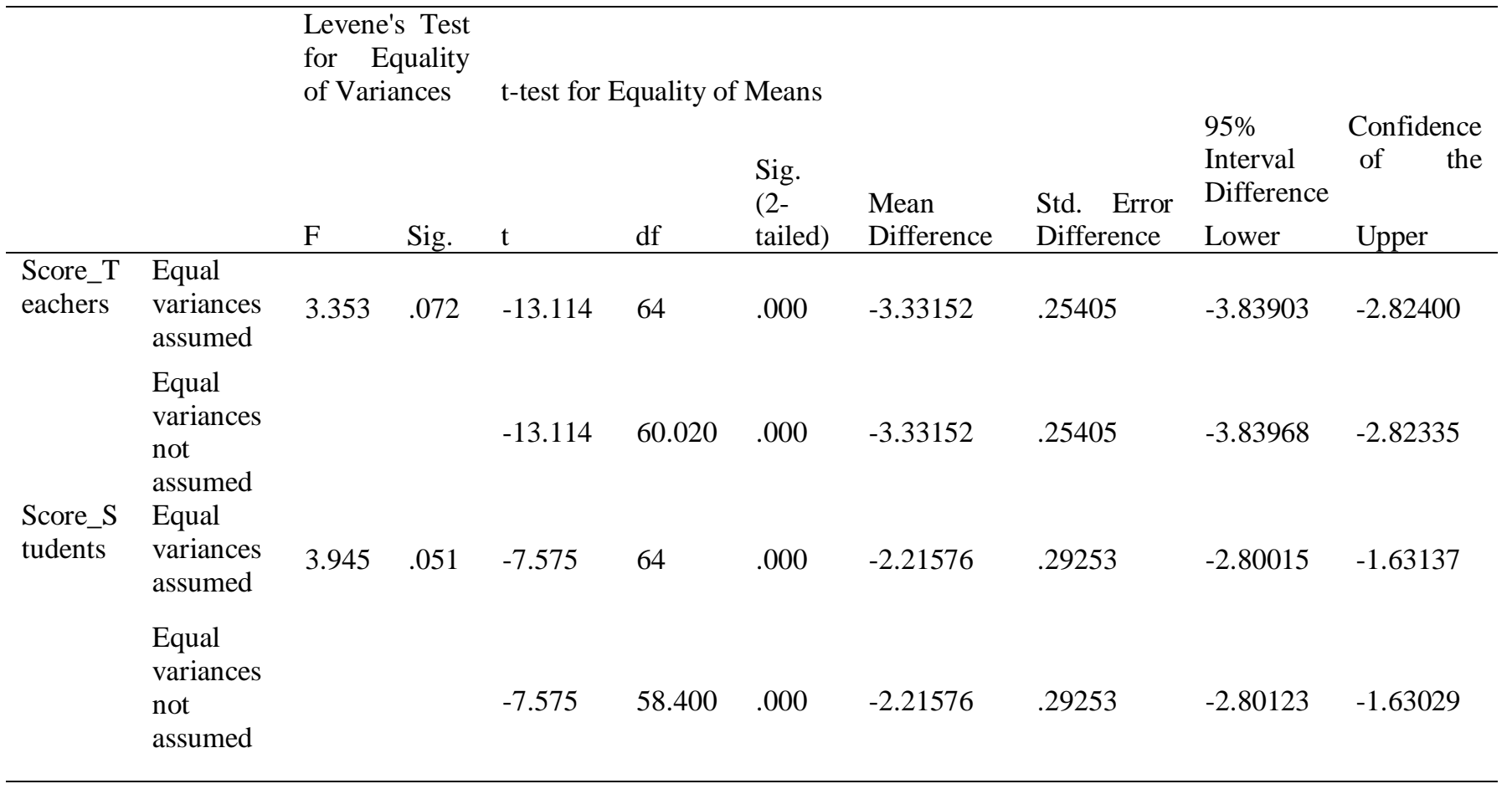


A point-biserial correlation analysis was performed for the variables: Score_Teachers, Score_Students and Pre_Post_Test. The results showed strong and significant $[p<.001, C I$ 95\%] positive correlations between all pairs of variables (see Table 4). i.e. higher mean scores are more characteristic for the post-test and higher scores for teachers translate into higher scores for students (see Figure 1).

Table 4

Point-Biserial Correlation Analysis

\begin{tabular}{|c|c|c|c|c|}
\hline & & Score_Teachers & Score_Students & Pre_Post_Test \\
\hline \multirow[t]{3}{*}{ Score_Teachers } & $\begin{array}{l}\text { Pearson } \\
\text { Correlation }\end{array}$ & 1 & $.625^{* *}$ & $.854^{* *}$ \\
\hline & Sig. (2-tailed) & & .000 & .000 \\
\hline & $\mathrm{N}$ & 66 & 66 & 66 \\
\hline \multirow[t]{2}{*}{ Score_Students } & $\begin{array}{l}\text { Pearson } \\
\text { Correlation }\end{array}$ & $.625^{* *}$ & 1 & $.688^{* *}$ \\
\hline & $\begin{array}{l}\text { Sig. (2-tailed) } \\
\mathrm{N}\end{array}$ & $\begin{array}{l}.000 \\
66\end{array}$ & 66 & $\begin{array}{l}.000 \\
66\end{array}$ \\
\hline \multirow[t]{3}{*}{ Pre_Post_Test } & $\begin{array}{l}\text { Pearson } \\
\text { Correlation }\end{array}$ & $.854^{* *}$ & $.688^{* *}$ & 1 \\
\hline & Sig. (2-tailed) & .000 & .000 & \\
\hline & $\mathrm{N}$ & 66 & 66 & 66 \\
\hline
\end{tabular}

**. Correlation is significant at the 0.01 level (2-tailed).

Figure 1

Scatter plot of correlation between teacher and student mean scores

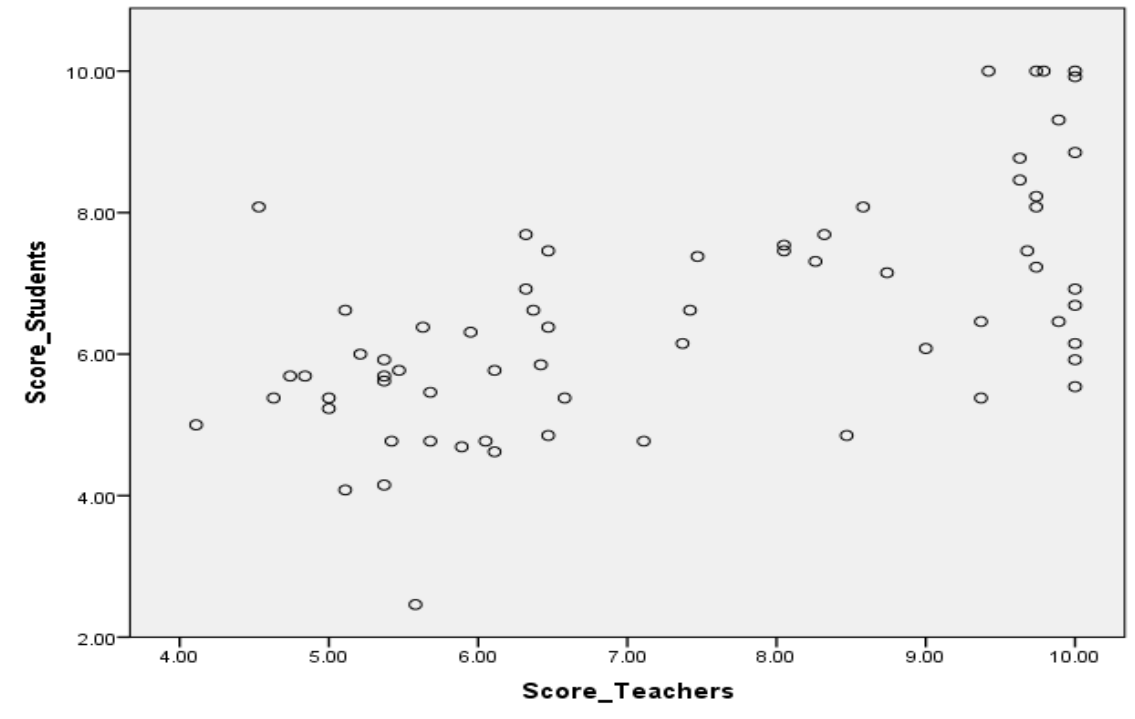




\section{International Journal of Medical Science and Health Research}

Vol. 5, No. 03; 2021

ISSN: $2581-3366$

\subsection{Community mobilization}

For the health promotion campaign purposes, one of the most popular Georgian poet elaborated the slogans.

A wide variety of information materials have been developed and distributed: 1. Each project year, the street billboards displaying the project logo and slogan were placed in the respective municipalities of Adjara; 2. The project has developed a Facebook site, where all project events and information materials were highlighted; 3 . The project produced a series of popular and technical videos on handwashing techniques as well as general advises on proper WASH practices. The videos have been aired through the local and national TV channels (including the period of COVID-19 pandemic); 4. The project has also developed a smartphone app on handwashing for IOS and Android; 5. In different forms, the project was organizing the celebrations of Global Handwashing Day. The largest event was held at Batumi Piazza; 6. A WASH awareness raising seminar was held for the journalist corps in Adjara; 7. Each year was concluded by the inauguration ceremonies at target schools and the annual conference.

Special WASH kits have been prepared for the WASH target sites. The kits have been distributed at all project events. Basic WASH information-containing booklets, leaflets, posters, T-shirts and branded bracelets have been included in the "WASH Kits".

The community mobilization tasks as well as overseeing the project implementation process have been materialized by the "WASH Committees", set in all 33 target villages.

\section{Discussion and policy implications}

All three components of the effort proved to be quite successful i.e. 4,202 school children in the target regions have substantially improved water supply, toiletry, sanitation and hygienic habits and skills. Additionally, 330 teachers and 330 peer educators have been trained around WASH issues. Although we had no specific means to measure the long-term outcomes of the community mobilization component, the scale of project's media production outreach exceeded the initially planned limits (local and regional) as opposed to the dissemination at national level. Our findings are comparable with the published evidence on WASH interventions applied in rural settings elsewhere (Crosby et al., 2020). The peer educators' component from the present study positively resonates with the concepts stipulated in a study which estimated the effectiveness of passing handwashing messages from "children to children" compared to the traditional teaching (Rutter et al., 2020). The successful application of the complex WASH interventions evidenced on multiple occasions in the scientific press (Caruso et al., 2014) (Gelaye et al., 2014) has been also confirmed by our observations.

The project has also contributed to evolving other beneficial "by-products" of which, we provide a short summary below.

The project has developed a fruitful cooperation with the following public and private entities: 1 . Palmolive-Colgate company, which has been donating free toothbrushes, toothpastes, liquid soap and health education materials to the project. This component covered 17 schools and 2,040 


\section{International Journal of Medical Science and Health Research}

Vol. 5, No. 03; 2021

ISSN: $2581-3366$

children; 2. Piazza Batumi provided a free venue for project events; 3. Department of Public Health of Tbilisi State Medical University, provided methodological assistance to the project; 4. Zhvania Pediatric Teaching Hospital of Tbilisi State Medical University, provided free health check-ups for project's target school students; 5. Peace Corps (USA) volunteers conducted "Clean Hands Lessons" in English.

As a response to the ongoing COVID-19 pandemic, the project provided information leaflets for public distribution and broadcasted the videos on handwashing through the major national TV channels.

\section{Conclusion}

The documented success of our WASH intervention approach as well as the available international evidence prompt us to consider the "Triple Element" (infrastructure, education and community mobilization) WASH in Schools principle as the optimal modality for implementing in low and middle income countries. Exclusion of any of these elements will adversely affect intervention's overall impact and importantly enough - its long-term sustainability. The "Triple Element" model seems to be easily scalable in Georgia and we also foresee the good prospects for its transferability to the countries with the similar socio-economic characteristics (the former Soviet Union states).

\section{Acknowledgments}

The authors would like to extend their sincere gratitude to the main donors of the intervention: USAID and the Coca-Cola Foundation. We are extremely thankful to all in-kind contributors, such as: Colgate-Palmolive, Tbilisi State Medical University, Zhvania Pediatric Teaching Hospital, Piazza Batumi and Peace Corps. We express our special appreciation to the regional education authorities, participating schools, teachers and students for their engagement and exceptional commitment.

\section{References}

Brewster David, Bailie Ross, McDonald Elizabeth, \& Morris Peter. (2008). Are hygiene and public health interventions likely to improve outcomes for Australian Aboriginal children living in remote communities? A systematic review of the literature. BMC Public Health, 8(1), 153-153. https://doi.org/10.1186/1471-2458-8-153

Caruso, B. A., Freeman, M. C., Garn, J. V., Dreibelbis, R., Saboori, S., Muga, R., \& Rheingans, R. (2014). Assessing the impact of a school-based latrine cleaning and handwashing program on pupil absence in Nyanza Province, Kenya: A cluster-randomized trial. Tropical Medicine \& International Health, 19(10), 1185-1197.

Coates, S., Ricketts, S., Vale, S., \& Hitchcock, C. (2010). Transferring personal hygiene and sanitation education (PHASE): South to North. Waterlines, 29(4), 315-328. 


\section{International Journal of Medical Science and Health Research}

Vol. 5, No. 03; 2021

ISSN: 2581-3366

Coswosk, É. D., Neves-Silva, P., Modena, C. M., \& Heller, L. (2019). Having a toilet is not enough: The limitations in fulfilling the human rights to water and sanitation in a municipal school in Bahia, Brazil. BMC Public Health, 19(1), 137. https://doi.org/10.1186/s12889-019-6469-y

Crosby, S., Laird, K., \& Younie, S. (2020). Children and handwashing: Developing a resource to promote health and well-being in low and middle income countries. Health Education Journal, 79(2), 123-137. https://doi.org/10.1177/0017896919866227

Dingman, D., Wu, J., \& Murphy, H. M. (2020). School-based, blacklight handwashing program can improve handwashing quality and knowledge among pre-school aged children. $\begin{array}{lllll}\text { Evaluation and Program } & \text { Planning, } & 78, & \end{array}$ https://doi.org/10.1016/j.evalprogplan.2019.101731

Dreibelbis, R., Freeman, M. C., Greene, L. E., Saboori, S., \& Rheingans, R. (2014). The impact of school water, sanitation, and hygiene interventions on the health of younger siblings of pupils: A cluster-randomized trial in Kenya. American Journal of Public Health, 104(1), e91-97. https://doi.org/10.2105/AJPH.2013.301412

Dreibelbis, R., Kroeger, A., Hossain, K., Venkatesh, M., \& Ram, P. K. (2016). Behavior Change without Behavior Change Communication: Nudging Handwashing among Primary School Students in Bangladesh. International Journal of Environmental Research and Public Health, 13(1). https://doi.org/10.3390/ijerph13010129

Gelaye, B. ( 1, 2 ), Williams, M. a. ( 2 ), Kumie, A. ( 3, 4 ), Berhane, Y. ( 4 ), \& Aboset, N. ( 5 ). (2014). School-based intervention: Evaluating the role of water, latrines and hygiene education on trachoma and intestinal parasitic infections in Ethiopia. Journal of Water Sanitation and Hygiene for Development, 4(1), 120-130. https://doi.org/10.2166/washdev.2013.060

Gizaw, Z. ( 1 ), Dagne, H. ( 1 ), \& Addisu, A. ( 2 ). (2019). Effects of water, sanitation and hygiene (WASH) education on childhood intestinal parasitic infections in rural Dembiya, northwest Ethiopia: An uncontrolled before-and-after intervention study. Environmental Health and Preventive Medicine, 24(1). https://doi.org/10.1186/s12199-019-0774-z

Graves, J. M., Daniell, W. E., Harris, J. R., Obure, A. F. X. O., \& Quick, R. (2011). Enhancing a safe water intervention with student-created visual aids to promote handwashing behavior in Kenyan primary schools. International Quarterly of Community Health Education, 32(4), 307-323. https://doi.org/10.2190/IQ.32.4.d

Harrison, J. a. (2012). Teaching children to wash their hands-Wash Your Paws, Georgia! Handwashing education initiative. Food Protection Trends, 32(3), 116-123.

Hawthorne $\quad$ effect. $\quad$ (2021). In $\quad$ Wikipedia. https://en.wikipedia.org/w/index.php?title=Hawthorne_effect\&oldid=1023974264 


\section{International Journal of Medical Science and Health Research}

Vol. 5, No. 03; 2021

ISSN: 2581-3366

Jess, R. L., \& Dozier, C. L. (2020). Increasing handwashing in young children: A brief review. Journal of Applied Behavior Analysis, 53(3), 1219-1224. https://doi.org/10.1002/jaba.732

Karon, A. J., Cronin, A. A., Cronk, R., \& Hendrawan, R. (2017). Improving water, sanitation, and hygiene in schools in Indonesia: A cross-sectional assessment on sustaining infrastructural and behavioral interventions. International Journal of Hygiene and Environmental Health, 220(3), 539-550. https://doi.org/10.1016/j.ijheh.2017.02.001

Kenyan school book knowledge for water, sanitation, hygiene and health education interventions: Disconnect, integration or opportunities? (2021). International Journal of Hygiene and Environmental Health, 235, 113756. https://doi.org/10.1016/j.ijheh.2021.113756

Kochurani Mathew, Suma Zachariah, Kathleen Shordt, Marielle Snel, Sandy Cairncross, Adam Biran, \& Wolf-Peter Schmidt. (2009). The sustainability and impact of school sanitation, water and hygiene education in southern India. Waterlines, 28(4), 275-292.

Nzengya, D. m. (2015). The impact of a school-based hygiene education intervention on student knowledge in Kenya. Journal of Water Sanitation and Hygiene for Development, 5(2), 271-278. https://doi.org/10.2166/washdev.2015.134

Öncü, E., Vayısoğlu, S. K., Lafci, D., Yurtsever, D., Bulut, E. R., \& Peker, E. (2019). Comparison of Interactive Education Versus Fluorescent Concretization on Hand Hygiene Compliance Among Primary School Students: A Randomized Controlled Trial. Journal of School Nursing, 35(5), 337-347. https://doi.org/10.1177/1059840518785447

Ozcan, A., Ozdil, K., Kaya, S. S., \& Sezer, F. (2020). Hand Washing in Primary School Students Using "Demonstration, Puzzle, Dance, Song": A Nursing Project Based on Multifaceted Skills Training. Journal of Continuing Education in Nursing, 51(4), 158-166. https://doi.org/10.3928/00220124-20200317-05

Pasewaldt, S. E., Baller, S. L., Blackstone, S. R., \& Bryan Malenke, L. (2019). Impact of a Hand Hygiene Curriculum and Group Handwashing Station at Two Primary Schools in East Africa. International Quarterly of Community Health Education, 39(3), 175-187. https://doi.org/10.1177/0272684X18819968

Rutter, S., Stones, C., \& Macduff, C. (2020). Communicating Handwashing to Children, as Told by Children. Health Communication, 35(9), 1091-1100. https://doi.org/10.1080/10410236.2019.1613478

Song, I. H., Kim, S.-A., \& Park, W.-S. (2013). Family factors associated with children's handwashing hygiene behavior. Journal of Child Health Care, 17(2), 164-173. 
Thakadu, O. T., Ngwenya, B. N., Phaladze, N. A., \& Bolaane, B. (2018). Sanitation and hygiene practices among primary school learners in Ngamiland district, Botswana. Physics and Chemistry of the Earth, 105, 224-230. https://doi.org/10.1016/j.pce.2018.02.006

Tidwell, J. B., Gopalakrishnan, A., Unni, A., Sheth, E., Daryanani, A., Singh, S., \& Sidibe, M. (2020). Impact of a teacher-led school handwashing program on children's handwashing with soap at school and home in Bihar, India. PloS One, 15(2), e0229655. https://doi.org/10.1371/journal.pone.0229655

Vally, H., McMichael, C., Doherty, C., Li, X., Guevarra, G., \& Tobias, P. (2019). The Impact of a School-Based Water, Sanitation and Hygiene Intervention on Knowledge, Practices, and Diarrhoea Rates in the Philippines. International Journal of Environmental Research and Public Health, 16(21), 4056. https://doi.org/10.3390/ijerph16214056 